\title{
An Analysis of Externality Economy of Xinjiang Water Resource Development
}

\author{
Changyuan Gao \\ Xinjiang Provincial Investigation \\ Design and Research Institute of Water Conservancy and Electric Power, Urumqi 830000, China \\ E-mail: gcy600909@163.com
}

\begin{abstract}
By analyzing the externality of Xinjiang water resource development in perspective economy, this paper advances suggestions on how to develop and use water resources reasonably and how to protect and govern ecological environment.

Keywords: Water resource development, Externality, Ecological environment

Externality means the impacts of one person or enterprise on others' welfare. If the impact is harmful, it is "negative externality". If the impact is favorable, it is "positive externality". Externality is sorted into the externality in production and the one in consumption. Here, we mainly discuss the externality in production. In other words, the effect or cost generated in production directly influences certain economic subject without exchange in market.
\end{abstract}

\section{External economy}

\subsection{Market equilibrium in external economy}

External economic effect means the positive externality effect (the economic benefit) generated in production, not by exchange in market. In other words, although these economic subjects do not pay for the economic benefit, they can enjoy certain interests.

Next, we will discuss the diversified public welfare of ground water resource development.

In Xinjiang, around the downstream of one river or the nearby of ground water overflow, the soil is thin and the ground water has a small slope, where the water level is usually between 1 and 3 meters. The groundwater evaporation is strong. The groundwater is supplied horizontally and the exit is mainly evaporation. Due to the strong evaporation, the salt does not go with water. It stays in soils. As time passes, soils tend to be salinification. As a result, the soil is not good for plants. Therefore, the ecological environment there is worse in general. However, the groundwater resource is rich. Because this area is far from surface water resources, irrigation is hard in spring. And due to the effect of evaporation, the superficial groundwater is not right for irrigation. The developers develop commercial groundwater and sell them to farmers in order to gain more profits. Due to the commercial exploitation of groundwater, the critical depth of groundwater evaporation is lower than 5 meters. Because of the decrease of evaporation, salt comes with water and goes with water. As a result, the quality of soil will be improved. All residents and farmers benefit from this externality economic effect but not pay for it. It is impossible for developers getting profits from residents and farmers.

Figure 1 reflects that the market equilibrium in external economy is not the optimal state of resource allocation. In Figure 1, D is the demand curve of groundwater resource (the sum of all farmers' needs in water resource area and the downstream area). SD is the groundwater's social demand curve (it is equal to the social marginal valuation). $\mathrm{S}$ is the supply curve of groundwater resource. SD is above D because water resource can improve soils and ecological environment. It has external economy. The difference of SD and D in vertical axis means the quantity of external economy. D indicates that the price of groundwater changes along with the consumption of groundwater. Because the external economy is not valued by money in groundwater market or traded by market, the supply-and-demand balance in groundwater resource market is the point e where $\mathrm{SD}$ and $\mathrm{D}$ reach. In Figure $1, \mathrm{Q}_{1}$ is the quantity of groundwater resource in supply-and-demand balance. $\mathrm{P}_{1}$ is the price of groundwater resource in supply-and-demand balance.

Next we discuss the condition of maximum social economic surplus including the external economy. Under this condition, the intersection point $\mathrm{f}$ determines the quantity of groundwater in exploitation, namely $\mathrm{Q}_{2}$ (Figure 1 ). Here, the maximum social economic surplus including the external economy is the area acf, which is larger than the social 
economic surplus in market equilibrium by an area def. In other words, the groundwater's market equilibrium can not achieve the social expected quantity of groundwater in exploitation. It is a "less production" phenomenon.

\subsection{External economy and price policy}

We still take the exploitation of groundwater as an example. By discussing the price policy, we hope to realize the optimal quantity of groundwater in exploitation as social expected. Next, we illustrate this point by Figure 2 (all characters, prices, quantities, and curves have same meanings with that in Figure 1).

(1) Price allowance policy

In Figure 2, in order to reach the exploitation quantity $\mathrm{Q}_{2}$, the government applies a price allowance policy, providing allowances for groundwater developers. The allowance price is $\mathrm{P}_{4}$ and the market price is $\mathrm{P}_{3}$. The difference of price allowance and market price is $\mathrm{P}_{4}-\mathrm{P}_{3}$. The national allowance is the area $\mathrm{P}_{4} \mathrm{fiP}_{3}$. The groundwater developers' producer surplus is the area $\mathrm{P}_{4} f a$. The consumer surplus is the area $\mathrm{biP}_{3}$. The external economic effect is the area cfib. The social economic surplus caused by the implementation of price allowance is the area acf. Now, the social economic surplus reaches its maximum. However, we should notice that once the allowance price betrays away from the price $\mathrm{P}_{4}$, the social economic surplus will decrease. The more it betrays, the more the decrease is.

(2) Unified purchases and sales at higher prices

The government applies the policy of unified purchases and sales at higher prices in order to improve the exploitation quantity of groundwater to $\mathrm{Q}_{2}$. The purchase price is $\mathrm{P}_{4}$. As the government fixes the price as $\mathrm{P}_{4}$ as it allocates the resource to consumers, the producer surplus is the area $\mathrm{aP}_{4} \mathrm{f}$. The consumer surplus is the area $\mathrm{P}_{4} \mathrm{bh}$. The government financial burden is the area $\mathrm{Q}_{4} \mathrm{hfQ} \mathrm{Q}_{2}$. The external economic effect is the area cfib. After applying this policy, the social economic surplus is the area of acf subtracting $\mathrm{Q}_{4} \mathrm{hiQ} \mathrm{Q}_{2}$. Here, the social economic surplus is smaller than that in applying the price allowance policy. However, as the price of unified sales is equal to the market price, namely $\mathrm{P}_{3}$, the policy of unified purchases and sales at higher prices and the policy of price allowance will generate equal social economic surplus.

\section{External diseconomy}

\subsection{Market equilibrium in external diseconomy}

External diseconomy means the "negative externality" mentioned above. Here, it mainly refers to the negative externality in production. In other words, the costs generated in production happen directly among economic subjects without market exchange.

For example, construct a reservoir in plain in Xinjinag, which will cause the oil salinification and swamping, worsening the agricultural ecological environment. The irrigation in upstream is rough, which increases the supply of groundwater in downstream, causing the rise of water level there. As a result, it drives the salinification and swamping, worsening the agricultural ecological environment. The long-term over exploitation in upstream makes the water level decrease in downstream, leading to desertification and land sedimentation.

All these issues concern the negative externality in water resource development, which makes the social costs of water resource development and use are larger than producers' costs. The social cost of producing each unit product includes the producer's "private cost" and the cost generated by the effect of water resource development on certain economic subject.

Figure 3 means the market equilibrium in external diseconomy does not reach the optimal state of resource allocation.

$\mathrm{D}$ is the demand curve. $\mathrm{S}$ is the supply curve. SMC is the social marginal cost including external diseconomy.

SMC is above the curve $\mathrm{S}$ because the supply curve $\mathrm{S}$ is the marginal cost (private marginal cost) taken directly by the water resource developer, excluding the cost of external diseconomy. SMC stands for the social marginal cost that includes the external diseconomy (because the worse agricultural economical environment). Therefore, the difference a between curve SMC and curve S in the vertical axis means the external diseconomy generated by the developer in developing water resources. The market equilibrium of water resources is determined by the intersection $\mathrm{f}$ between curve $\mathrm{D}$ and curve $\mathrm{S}$. The price in supply-and-demand equilibrium is $\mathrm{P}_{1}$, and the quantity in supply-and-demand equilibrium is $\mathrm{Q}_{2}$. The consumer surplus is the area $\operatorname{cfP}_{1}$. The external diseconomy (loss) is the area abgf. The social economic surplus is the part of the area bce subtracting the area egf.

Considering the existence of external diseconomy, the quantity of water resource exploitation is $\mathrm{Q}_{1}$ as the social economic surplus reaches the maximum. Here, the social economic surplus is the area bce. In conclusion, at the state of market equilibrium, there is $\left(\mathrm{Q}_{2}-\mathrm{Q}_{1}\right)$ exploitation surplus, which will cause the social economic surplus, namely the area cgf. 


\subsection{Countermeasures for external diseconomy}

In order to depress the exploitation surplus generated in Figure 3 and the decrease of social economic surplus due to exploitation surplus, we must increase the producer's "private marginal cost". In other words, move the curve S upward as much as possible, being close or equal to curve SMC.

(1) Internalized the external diseconomy

The government can delete or reduce the external diseconomy by relevant laws, policies, and administrative regulations. For example, set restrictions on building reservoirs in plains and forbidden over exploitation of water resources in upstream area. By this way, water resource developers will have to increase their "private marginal cost". As a result, less water resources will be developed. To intake the social cost generated by external diseconomy into the production will turn into the "private cost". Therefore, it is named as the "internalization" of external diseconomy.

For example, in Xinjiang a developer wants to develop a new land. The developer builds a reservoir in the plain in upstream (if permitted) and makes agricultural production in downstream. In this area, the groundwater level is relatively higher: the upstream is about 3-8 meters and the downstream 1-3 meters. Soils contain more salt. After the construction of reservoir, the groundwater level will be higher due to the leakage of reservoir, worsening the agricultural production environment. The developer should build facilities to avoid the rise of groundwater level: construct a new water resource and exploit the groundwater. Along with the decrease of groundwater level and the decline of groundwater evaporation, the chance for generating more salts in oils will be few. Then, the soil and the ecological environment in this area will be improved, which increases the economic benefits of the developer.

(2) Set up the most appropriate restrict standards

To set up the most appropriate restrict standards, we must take the disappearance of oil salinification, desertification, and land sedimentation, the decrease of external diseconomy's expenses, and the decrease of external diseconomy's losses into consideration. In Figure 4, the lateral axis stands for the level depth. Suppose the level depth is h. For agricultural plants, the ideal value is h0. As this value is less than 5 meters, the marginal effect curve is the social marginal effect generated along with the rise of this value. As the value is equal to or higher than 5 meters, the marginal effect curve is the social marginal effect generated along with the decrease of this value.

In the example above, the developer is to develop a reservoir but not perform agricultural production. The developer must build a facility to decrease the groundwater level in area where the level depth is less than 5 meters: develop a water resource and exploit the groundwater. Along with the rise of groundwater level depth and the decrease of groundwater evaporation, less chance for oils obtaining more salts there. By this way, it improves the oils and ecological environment in the area. The developer's economic benefits will be rising. The marginal cost curve stands for the marginal cost generated by groundwater exploitation.

The most appropriate restrict standard is determined by the intersection of the marginal effect curve and the marginal cost curve, namely m. In Figure 4, h1 is the most appropriate restrict standard. For the developer, if the groundwater level depth in downstream area, he or she will be punished by the government.

Here we should notice that the most appropriate restrict standard is not necessary to make the external diseconomy in a "zero" state (the ideal groundwater level depth is h0). The pure social return generated by the most appropriate restrict standard $\mathrm{h} 1$ is the area $\mathrm{jkm}$.

(3) Taxation

Impose more taxes on the developer who causes the appearance of external diseconomy, improving their costs for worsening the environment.

(4) The developer should pay for their exploitation, compensating the victims in the area and improving the worsening environment.

\section{References}

Gao, Changyuan. (1996). Reasons for high mineralized water in Anji ocean irrigation area. Xinjiang Water Conservancy. No.2.

Gao, Changyuan. (2000). Establish the optimal value of water level in dry area. Ground Water. No.3.

Zhang, Wenyuan. (2000). Experiment for the effective impacts of single well on soil. Ground Water. No.3. 


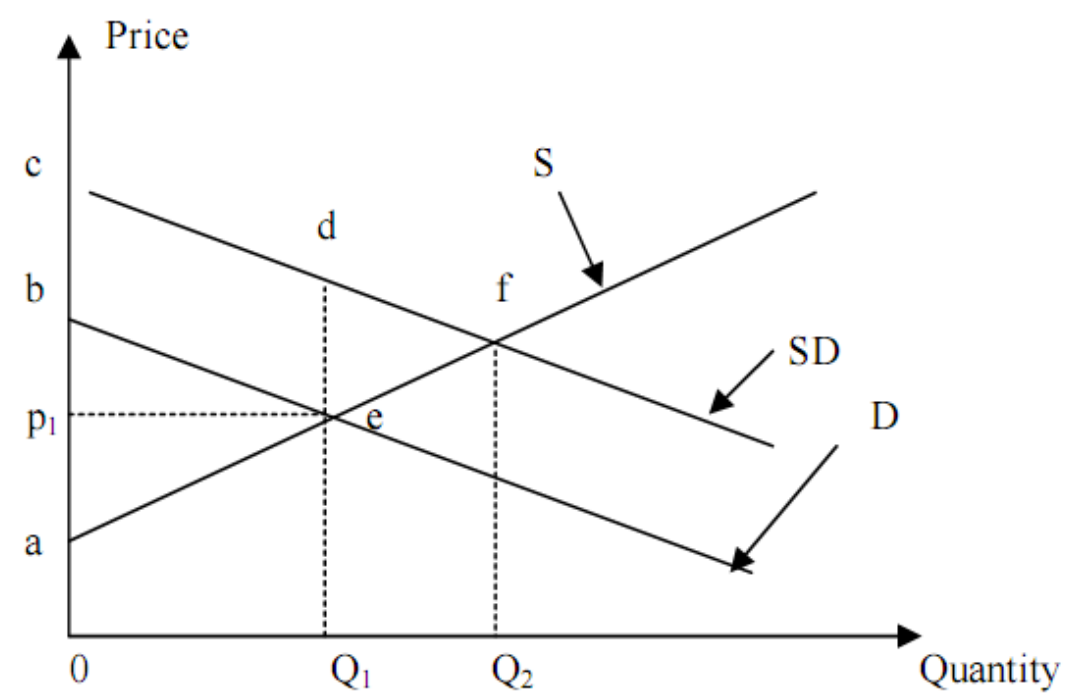

Figure 1. The Market Equilibrium in External Economy

\section{Price}

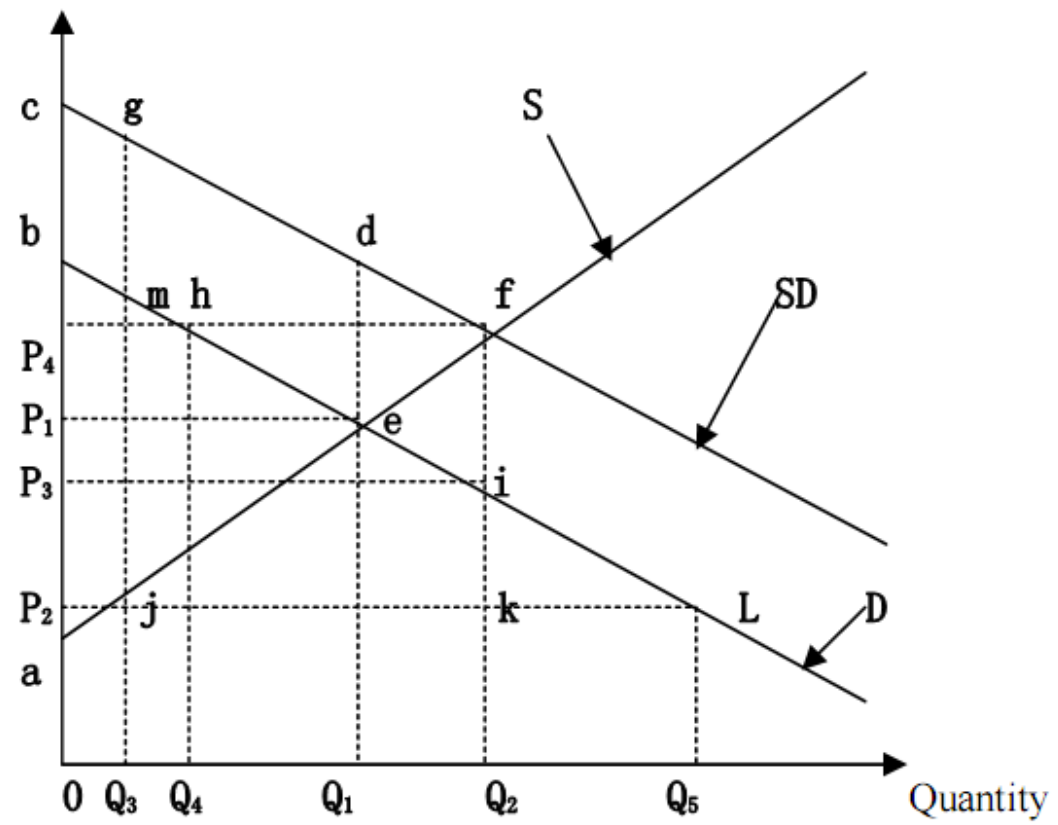

Figure 2. External Economy and Price Policy 


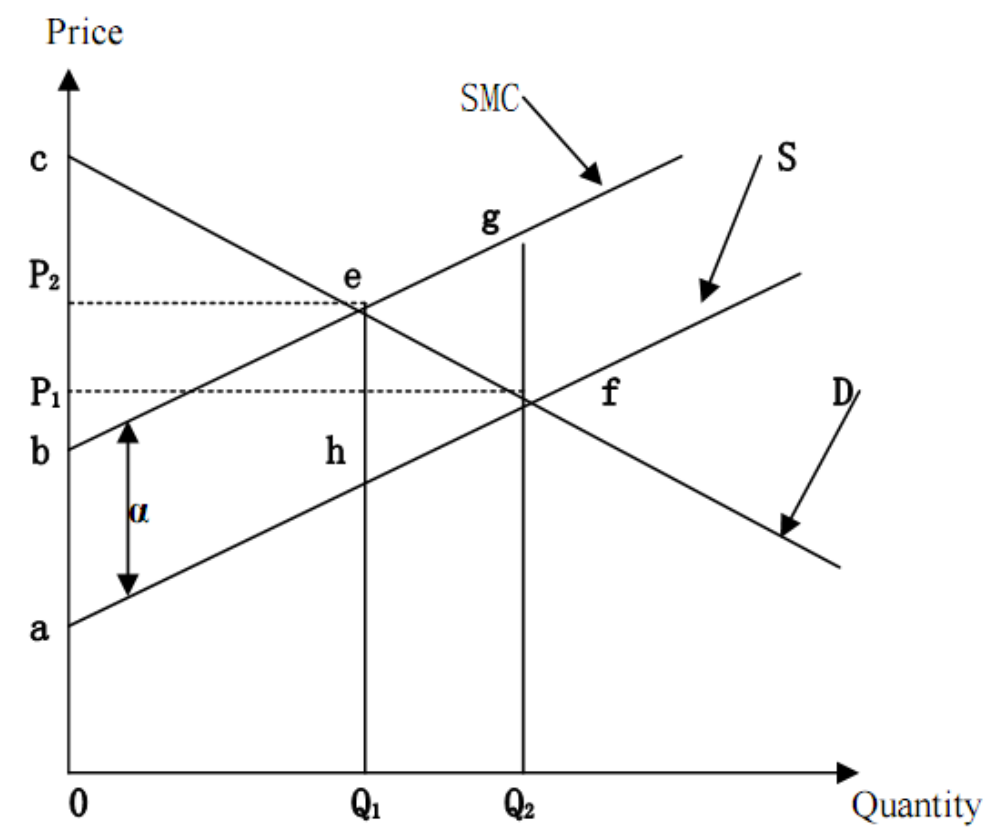

Figure 3. External Diseconomy and Market Equilibrium

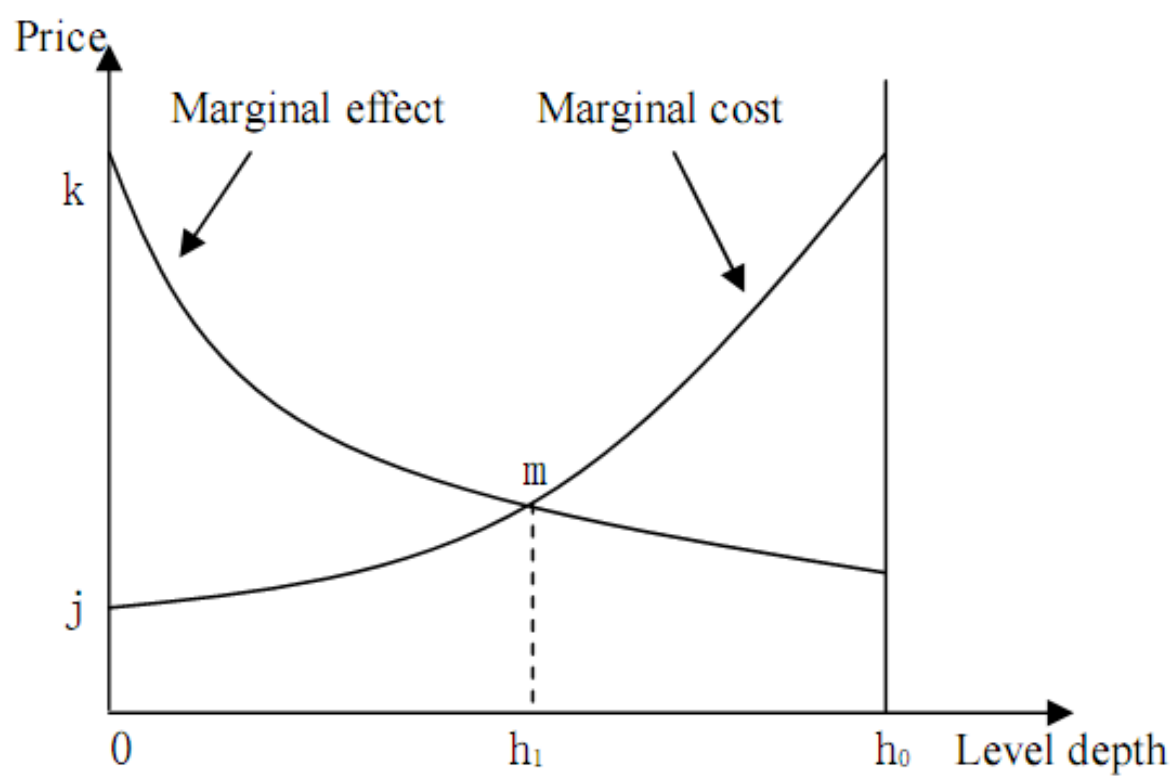

Figure 4. The Most Appropriate Restrict Standards 